\title{
Investigating the feasibility of using near-infrared spectroscopy for inline monitoring of the salt content in industrial process water
}

\author{
Kasper Borg Damkjær, ${ }^{*}$ Klavs Martin Sørensen and Søren Balling Engelsen \\ Chemometrics and Analytical Technology section, Department of Food Science, Faculty of Science, University of Copenhagen, Rolighedsvej 26, DK-1958, \\ Frederiksberg C, Denmark. ${ }^{*}$ E-mail: kasper@food.ku.dk
}

Fast real-time monitoring of water quality can help facilitate reuse of industrial process water. Near-infrared spectroscopy is a well-established process monitoring tool within the pharma and food industry. Utilising near-infrared spectroscopy as one of the pieces in the puzzle for optimising water reuse is therefore attractive. Partial least squares regression models were computed on 286 near-infrared spectra of mono salt solutions of $\mathrm{KCl}_{2} \mathrm{~K}_{2} \mathrm{SO}_{4}, \mathrm{KNO}_{3}, \mathrm{CaCl}_{2}$, $\mathrm{CaSO}_{4}$ and $\mathrm{Ca}\left(\mathrm{NO}_{3}\right)_{2}$. Concentrations ranging from $0 \mathrm{ppm}$ to $1000 \mathrm{ppm}(\mathrm{w} / \mathrm{w})$ in steps of $100 \mathrm{ppm}$ were measured at 10,25 and $40^{\circ} \mathrm{C}$. Analysis showed that the concentration of salt could be predicted independently from temperature resulting in a root mean squared error of cross validation, RMSECV, of $186 \mathrm{ppm}$ and an $R^{2}$ of 0.67 . A global temperature model and an individual model on $\mathrm{K}_{2} \mathrm{SO}_{4}$ at $25^{\circ} \mathrm{C}$ cross validated by leave-one-concentration-out resulted in RMSECV values of $181 \mathrm{ppm}$ and $115 \mathrm{ppm}$ and $R^{2}$ values of 0.68 and 0.87 . The limit of detection and limit of quantification for $\mathrm{K}_{2} \mathrm{SO}_{4}$ was estimated to be $140 \mathrm{ppm}$ and $400 \mathrm{ppm}$.

\section{Introduction}

In 1985 paper, Tomas Hirschfeld wrote that, "... at first glance, the determination of salinity by infrared spectroscopy is so implausible as to seem ridiculous". However, as Hirschfeld points out, inorganic salts in an aqueous solution will alter the shape and position of the water absorption bands, and hence, can be quantified. ${ }^{1}$ Near-infrared spectroscopy analysis has become a very attractive tool for process monitoring in the pharma and food industries (e.g. process analytical technology). Due to the price, speed and accuracy of this method, there is an industrial interest in exploiting the possibilities of applying near-infrared spectroscopy to solve water related production issues, particularly those related to sustainable water use and reuse. ${ }^{2}$ Better process understanding of filtration systems such as reverse osmosis is a key ingredient in reducing water consumption while increasing reuse of process water. This work represents a first step towards utilising the advantages in using near-infrared spectroscopy for inline water quality monitoring targeting quantification of

\section{Correspondence}

K.B. Damkjær (kasper@food.ku.dk)

doi: 10.1255/nir2017.023

Citation: K.B. Damkjær, K.M. Sørensen and S.B. Engelsen, "Investigating the feasibility of using near-infrared spectroscopy for inline monitoring of the salt content in industrial process water", in Proc. $18^{\text {th }}$ Int. Conf. Near Infrared Spectrosc., Ed by S.B. Engelsen, K.M. Sørensen and F. van den Berg. IM Publications Open, Chichester, pp. 23-29 (2019). https://doi. org/10.1255/nir2017.023 inorganic salts, a key performance parameter for membranes in reverse osmosis water filtration systems.

It was already established at the beginning of the $19^{\text {th }}$ century that salt and temperature can alter the height, width and position of the absorbance bands of water. One of the earliest investigations into how the near-infrared spectrum of aqueous solutions change as a function of salt type, salt concentration and temperature was performed in 1913 by Harry Clary Jones and James Samual Guy. ${ }^{3}$ The cause of these changes is related to the hydrogen bonding network of water. Increasing the temperature will decrease the strength of the hydrogen bonding network, which in turn will enable the $\mathrm{OH}$-bonds of the water molecules to vibrate at a higher frequency introducing a shift while decreasing the temperature will have the opposite effect (anharmonicity rule). Ions in a solution have a similar influence on the hydrogen bonding network of water. Depending on their charge and size, ions will influence this network similar to

\section{(C) 2019 The Authors}

This licence permits you to use, share, copy and redistribute the paper in any medium or any format provided that a full citation to the original paper is given, the use is not for commercial purposes and the paper is not changed in any way.

ISBN: 978-1-906715-27-4 
temperature. However, there is still not consensus on the specific hydration mechanisms and individual effects of ions on the hydrogen bonding network. Therefore, these effects are still being studied today, and it has been shown numerous times that these changes can be quantified in such a way that the salt concentration in an aqueous solution can be predicted by near-infrared spectroscopy. ${ }^{1,4-7}$ These authors report limits of detection (LoD) for $\mathrm{NaCl}$ to be in the area of $900-2300 \mathrm{ppm}$ in concentrations ranging from $0.01 \mathrm{M}$ to $10 \mathrm{M}(\sim 600-$ 600,000 ppm). These LoDs cannot be directly compared as they span different concentration ranges; as their models were validated differently and since the LoD were calculated according to different standards. However, their findings give an indication of the detection limits of salts in general throughout the last 30 years.

In this proceeding we present a part of the results from the first steps of the investigation of the feasibility for using near-infrared spectroscopy to monitor the salt content in industrial process water. In a systematic experimental design optimised to achieve a high signal-tonoise ratio we show how the concentration of aqueous mono mixtures of salt can be predicted and establish the limit of detection and quantification of individual salts.

\section{Materials and methods}

\section{Preparation of salt solutions}

In this study six different salts were used: $\mathrm{KCl}, \mathrm{K}_{2} \mathrm{SO}_{4}$, $\mathrm{KNO}_{3}, \mathrm{CaCl}_{2}, \mathrm{CaSO}_{4}$ and $\mathrm{Ca}\left(\mathrm{NO}_{3}\right)_{2}$. All salts were purchased from VWR Chemicals (Søborg, Denmark) with a purity of $99 \%$ except $\mathrm{Ca}\left(\mathrm{NO}_{3}\right)_{2}$ which had a purity of $98 \%$. Each salt solution was prepared by making a $15,000 \mathrm{ppm}(\mathrm{w} / \mathrm{w})$ stock solution (the $\mathrm{CaSO}_{4}$ stock solution was $1000 \mathrm{ppm}$ due to low solubility), which was diluted to concentrations of $100-1000 \mathrm{ppm}(\mathrm{w} / \mathrm{w})$ in steps of $100 \mathrm{ppm}$. For each salt solution the stock solution was weighed off into a container, the weight noted, and Milli-Q water $(18.2 \mathrm{M} \Omega \mathrm{cm})$ added corresponding to the required concentration. To avoid potential contamination from glassware all solutions were made and stored in $250 \mathrm{~mL}$ polypropylene bottles (Product ID: S.061.22.901.030, ISOLAB GmbH, Wertheim, Germany). To minimise any degree of evaporation during the experimental period which ran over three weeks the salt solutions were, when possible, kept at $5^{\circ} \mathrm{C}$. Furthermore, over the duration of the experiment three control bottles were regularly weighed in order to monitor evaporation of the solution. Upon ending the experiment no significant evaporation of the solutions had occurred.

\section{Spectral measurements}

Spectral data on the salt solutions were acquired using an ABB MB3600 Fourier transform near-infrared spectrometer (Q-Interline A/S, Tølløse, Denmark) equipped with an InAs detector (830-2700 nm). An overview of the experimental design is shown in Figure 1. Single beam spectra were collected with Horizon MB ${ }^{\mathrm{TM}}$ FT-IR software (version 3.4.0.3, ABB, Quebec, Canada). All spectra were acquired in transmission mode using a $2 \mathrm{~mm}$ quartz cuvette optimising the $1^{\text {st }}$ and $2^{\text {nd }}$ overtone of water in the region from $907 \mathrm{~nm}$ to $1846 \mathrm{~nm}$. A lid was placed on top of the cuvette to avoid evaporation during measurements. Before each measurement the cuvette was thoroughly cleaned with Milli-Q water and ethanol. For temperature control, an aluminium cuvette

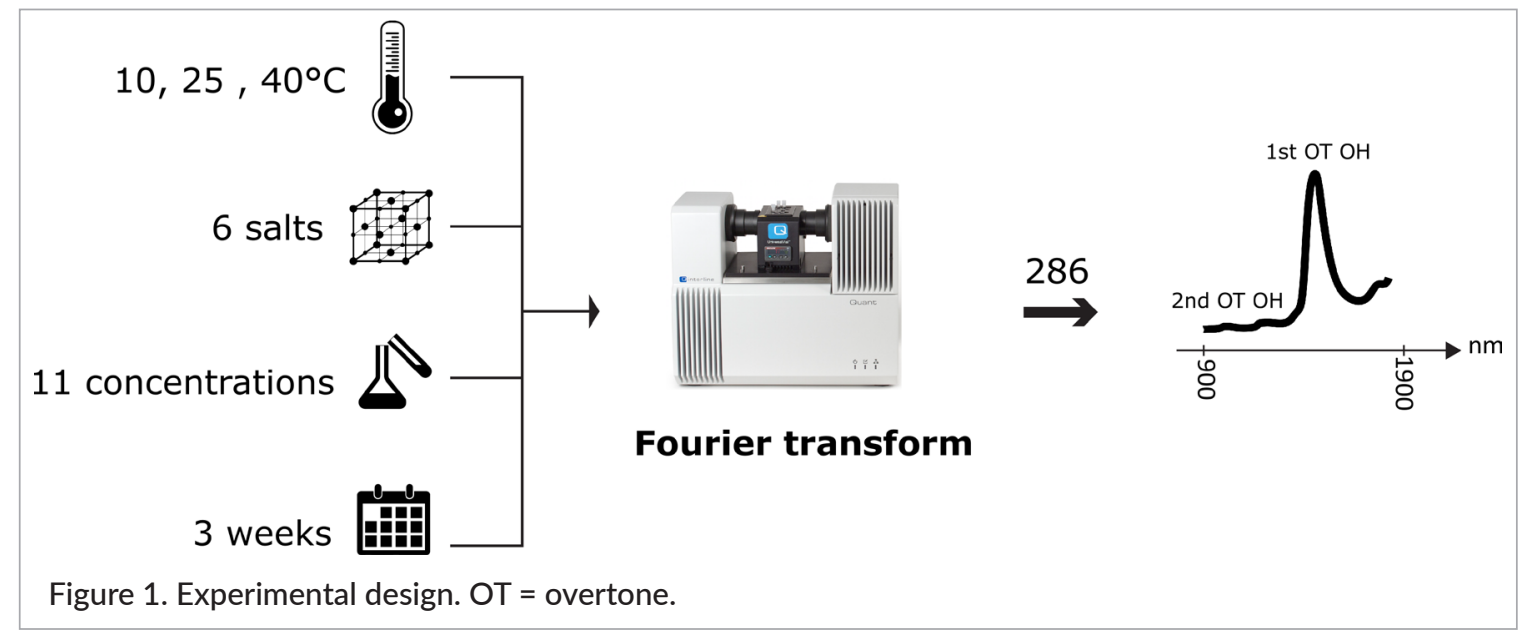


sample holder connected to a water bath (Haake Phoenix C25P, Thermo Electron Corporation, Germany) was used, enabling temperature control with an accuracy of $\pm 0.1^{\circ} \mathrm{C}$. Furthermore, the spectrometer was purged with dry atmospheric air to remove water vapour and thereby improve the spectral quality.

For each salt solution 2200 scans were acquired at a resolution of $32 \mathrm{~cm}^{-1}$ resulting in a 10 -minute acquisition time per spectrum. Each solution was measured at temperatures of 10,25 and $40^{\circ} \mathrm{C}$. Salt solutions of $\mathrm{Ca}\left(\mathrm{NO}_{3}\right)_{2}$ and $\mathrm{K}_{2} \mathrm{SO}_{4}$ were measured in triplicates at 10 and $25^{\circ} \mathrm{C}$. Due to time constraints triplicates were not measured at $40^{\circ} \mathrm{C}$. The samples were measured on 14 different days spanning a time period of three weeks. The measurement order of the samples was randomised within each temperature.

Reference spectra were obtained on an empty cuvette. In order to level out instrumental and temperature variations during each measurement 1100 spectra were collected before each sample measurement. The reference spectra before and after a measurement were then averaged and used for spectral correction.

At each temperature the samples were equilibrated in a water bath (13 DT-1, Heto-Holten A/S, Allerød, Denmark) before the measurement. When starting a reference or sample measurement the content of the cuvette, air or salt solution, were furthermore allowed to equilibrate for 5 minutes.

\section{Data analysis}

The spectral data matrix acquired by the ABB MB3600 had the dimensions 286 samples $\times 1024$ wavelengths. 110 samples at $10^{\circ} \mathrm{C}, 110$ samples at $25^{\circ} \mathrm{C}$ and 66 samples at $40^{\circ} \mathrm{C}$. As a starting point for chemometric analysis the wavelength region of $907-1846 \mathrm{~nm}$ was used resulting in 364 wavelengths.

In order to investigate if a global predictive model computed by partial least squares regression $(P L S)^{8}$ could be developed independently from temperature, principal component analysis (PCA) ${ }^{9}$ was applied in order to extract the main variation in the data arising from temperature observed in the first principal component. This was then subtracted the mean centred original data removing temperature effects before modelling.

Predictive models were computed at each temperature by PLS in range of $907-1846 \mathrm{~nm}$ on spectra preprocessed by mean centring. Models were cross validated by leave-one-concentration-out, leave-one-salt-out and leave-one-temperature-out on average removing 9, 17 and $33 \%$ of the data. Outlier detection was done based on a combination of PLS scores, PLS predictions, Hotelling's $T^{2}$ and $Q$ residuals. A sample was only removed from a model if the sample could be lead back to an experimental error. Of the 286 samples, 5 were removed upon analysis. In case of ambiguity concerning the number of PLS factors to include in a model, the lowest number of factors were always chosen in order to obtain a conservative estimate of the root mean squared error of cross validation, RMSECV.

All computations were made using MATLAB R2016b (The MathWorks, Natick, MA) and all chemometric models were developed under PLS Toolbox version 8.2.1 (Eigenvector Research, Inc., Wenatchee, WA).

\section{Estimating limit of detection and limit of quantification}

The author follows the guidelines of IUPAC ${ }^{10}$ to estimate the limit of detection (LOD) and limit of quantification (LoQ).

$$
x_{\mathrm{L}}=\bar{x}_{\mathrm{bi}}+k s_{\mathrm{bi}}
$$

where $\bar{x}_{\mathrm{bi}}$ is the mean of the blank measures, $s_{\mathrm{bi}}$ is the standard deviation of the blank measures and $k$ is a numerical factor chosen according to the confidence level desired. In this study $k=3$ for the LoD and $k=10$ for the LoQ.

\section{Results and discussion}

\section{Spectral features arising from temperature}

Figure 2 a displays the raw spectra of the salt solutions measured at 10,25 and $40^{\circ} \mathrm{C}$. It is evident that the spectra shift to lower wavelengths, with increasing temperature. The maximum absorbance of the band arising from the combined symmetric and antisymmetric $\mathrm{OH}$ stretching changes from $1456 \mathrm{~nm}$ to $1437 \mathrm{~nm}$ going from $10^{\circ} \mathrm{C}$ to $40^{\circ} \mathrm{C}$.

Figure $2 \mathrm{~b}$ shows difference spectra of Milli-Q water, measured on the same spectrometer under the same conditions as the main experiment, at temperatures from $15^{\circ} \mathrm{C}$ to $45^{\circ} \mathrm{C}$ in steps of $5^{\circ} \mathrm{C}$ calculated by subtracting a $10^{\circ} \mathrm{C}$ spectrum. The spectra are changing linearly with temperature at 963, 1154, 1412 and $1490 \mathrm{~nm}$ as has been observed previously. ${ }^{11,12}$ 

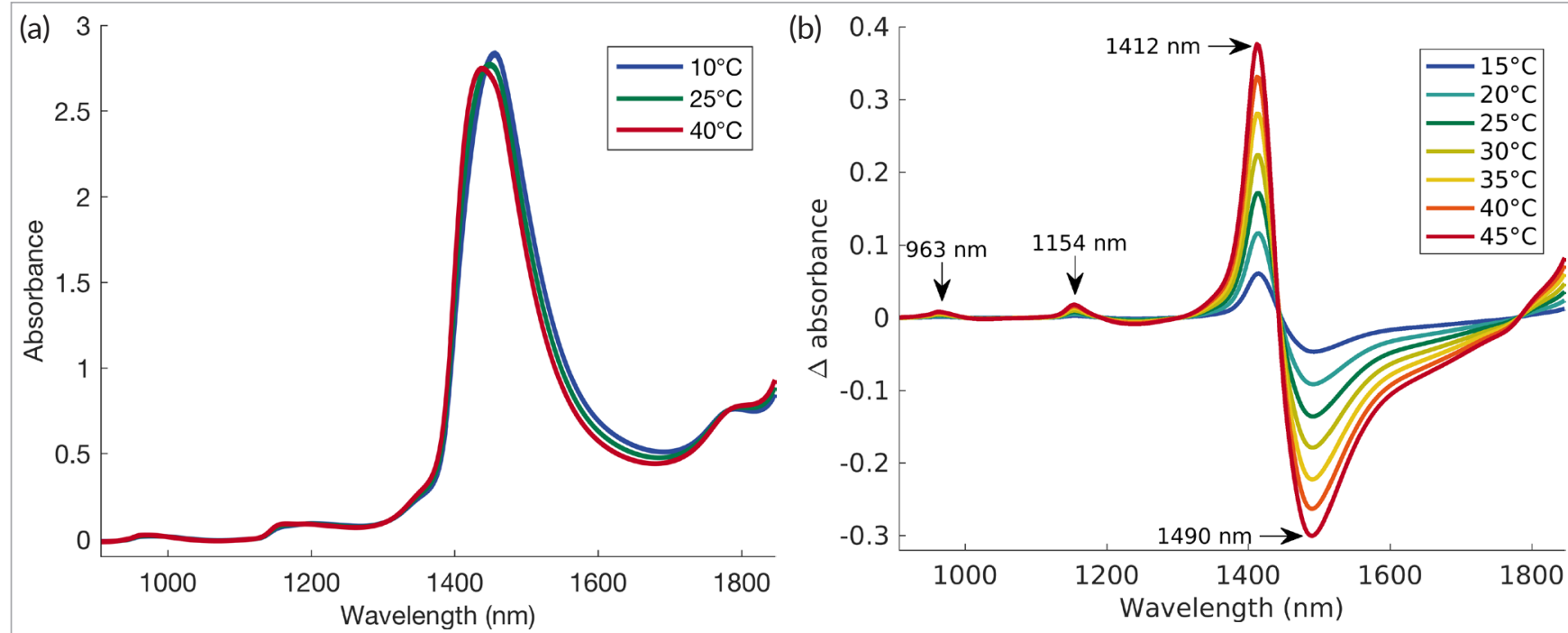

Figure 2. (a) Raw spectra of salt solutions measured at 10,25 and $40^{\circ} \mathrm{C}$. (b) Difference spectra of Milli-Q water from $15^{\circ} \mathrm{C}$ to $45^{\circ} \mathrm{C}$ calculated by subtracting a $10^{\circ} \mathrm{C}$ Milli-Q water spectrum.

\section{Predicting salt concentration independently from temperature}

Initial PLS models using a leave-one-temperature-out cross validation scheme showed that the salt concentration could not be predicted independently from temperature when common pre-processing methods were applied (data not shown). Various other approaches were investigated. The best solution proved to be subtracting the first principal component (scores multiplied by loadings) of a mean centred PCA model from the original mean centred data before predicting the salt concentration. Figure $3 a$ shows the first principal component which shares the same spectral features at 963, 1154, 1412 and $1490 \mathrm{~nm}$ arising from temperature as the difference spectra shown in Figure 3b. This confirms that these changes are related to temperature. Figure $3 b$ shows the spectral data after subtraction of the first principal component. As can be seen there is still some temperature information left in the spectra, but subtracting more PCA components did not improve the model. An RMSECV of $186 \mathrm{ppm}$ and an $R^{2}$ of 0.67 could be obtained for the global temperature model (data not shown) giving an estimate of how well new samples in the same concentration range, measured at an unknown temperature, will be predicted by the
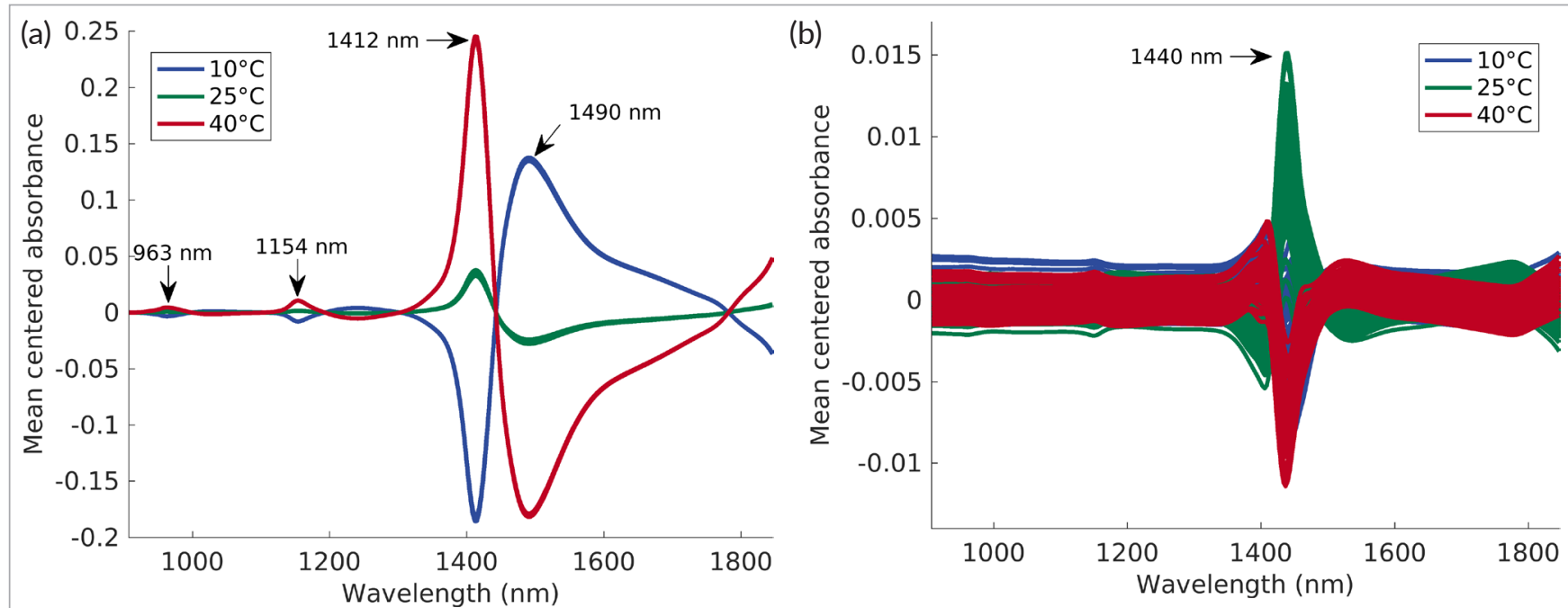

Figure 3. (a) First principal component of a mean centred PCA model. (b) Mean centred original data subtracted by the first principal component from a mean centred PCA model. 
model. In the case of a reverse osmosis filtration, where the temperature will fluctuate, being able to predict the salt concentration independently of temperature would be an attractive feature. However, temperature fluctuations in a reverse osmosis plant will typically not be as extreme as in our conditions.

In order to be able to compare models across combined and individual temperatures and individual salt types only cross validating by concentration or random is applicable. Figure 4a displays an actual versus predicted plot for a six-factor global temperature PLS model cross validated by leave-one-concentration-out having an RMSECV of $181 \mathrm{ppm}$ and an $R^{2}$ of 0.68 . It is evident that some salts are better predicted than others. The individual RMSECVs of the salts span from $163 \mathrm{ppm}$ for $\mathrm{K}_{2} \mathrm{SO}_{4}$ to $213 \mathrm{ppm}$ for $\mathrm{Ca}\left(\mathrm{NO}_{3}\right)_{2}$ (data not shown). $\mathrm{K}_{2} \mathrm{SO}_{4}$ concentration is in general predicted better than the concentration of $\mathrm{Ca}\left(\mathrm{NO}_{3}\right)_{2}$. This is not surprising as one would expect the salts to alter the spectra differently. ${ }^{3,4,6}$ The salts were prepared on a weight/weight basis. If there were no differences between how the salts affect the spectra one would expect the salts to be predicted with roughly the same error, and basically correspond to a dry matter determination. Apparently, this does not seem to be the case for this model and thus the differences in prediction errors may arrive from the different spectral changes due to salt type.

\section{Predicting salt concentration of an individual salt}

PLS models were made on the $\mathrm{K}_{2} \mathrm{SO}_{4}$ data. Figure $4 \mathrm{~b}$ display actual versus predicted plots of the model computed on mean centred $25^{\circ} \mathrm{C}$ data applying leaveone-concentration-out cross validation. With an RMSECV of $115 \mathrm{ppm}$ and an $R^{2}$ of 0.87 the individual salt model performs better than the global one.

The LoD and LoQ was calculated according to Equation 1 resulting in $140 \mathrm{ppm}$ and $400 \mathrm{ppm}$ for $\mathrm{K}_{2} \mathrm{SO}_{4}$. The LoD value is lower than what has been previously reported. ${ }^{5,7}$ These authors showed LoD values of 15 mM ( 900 ppm) and $1000 \mathrm{ppm}$ for $\mathrm{NaCl}$. However, as the LoDs have been based on different salts, concentrations ranges, calculations and validation schemes they are not directly comparable.

\section{Evaluation of the feasibility to predict the salt concentration in a reverse osmosis plant}

ICP-OES has been used to characterise the element composition and concentration of the permeate from a double reverse osmosis ( $R O$ ) filtration of whey from a production of cheese made from cow's milk. ${ }^{13}$ It was found that the most abundant element in the permeate was potassium with concentrations ranging from approximately 800 ppm in the feed into the first RO unit, and $5 \mathrm{ppm}$ in the permeate at the second RO unit (see
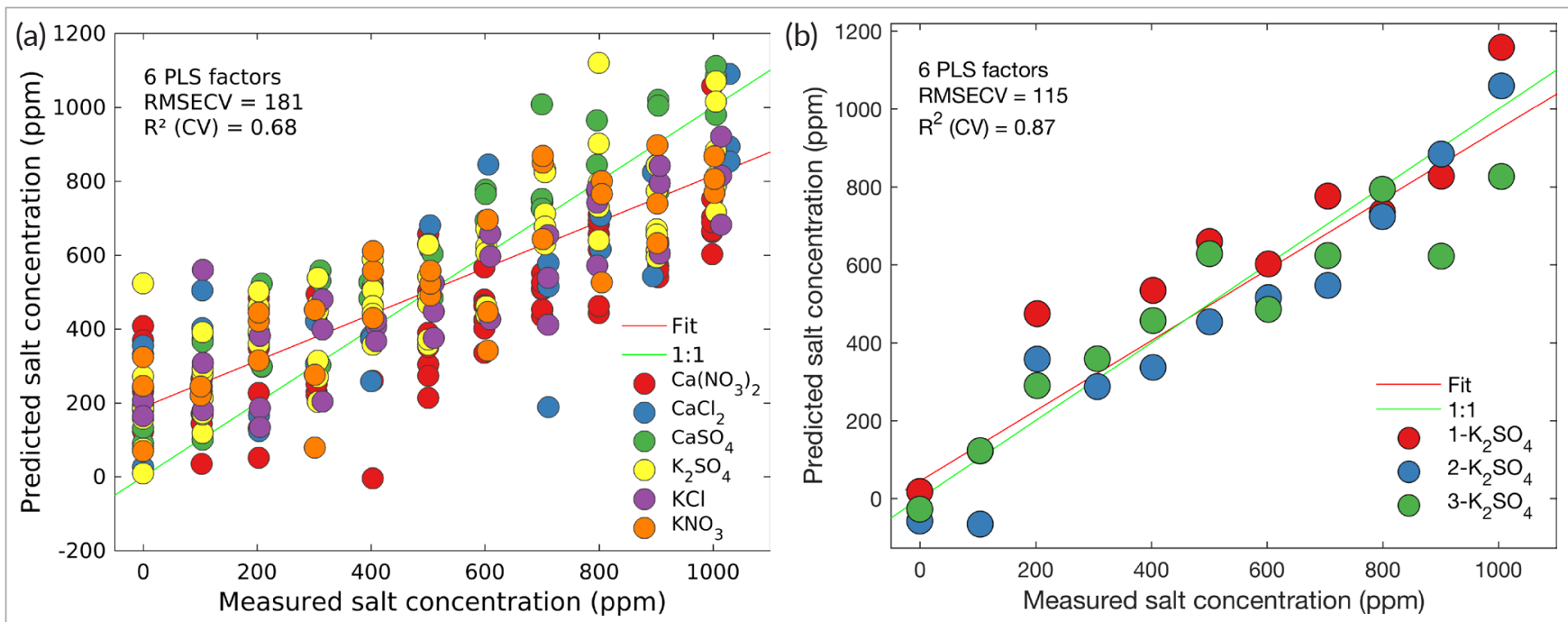

Figure 4. (a) Predicted versus measured plot from a mean centred PLS model made on 10,25 and $40^{\circ} \mathrm{C}$ data cross validated by leave-one-concentration-out. Coloured according to salt type. The original mean centred data were subtracted by the first principal component from a mean centred PCA model before analysis. (b) Predicted versus measured plot from a mean centred PLS model made on $25^{\circ} \mathrm{C}$ data cross-validated by leave-one-concentration-out. Coloured according to salt type. 


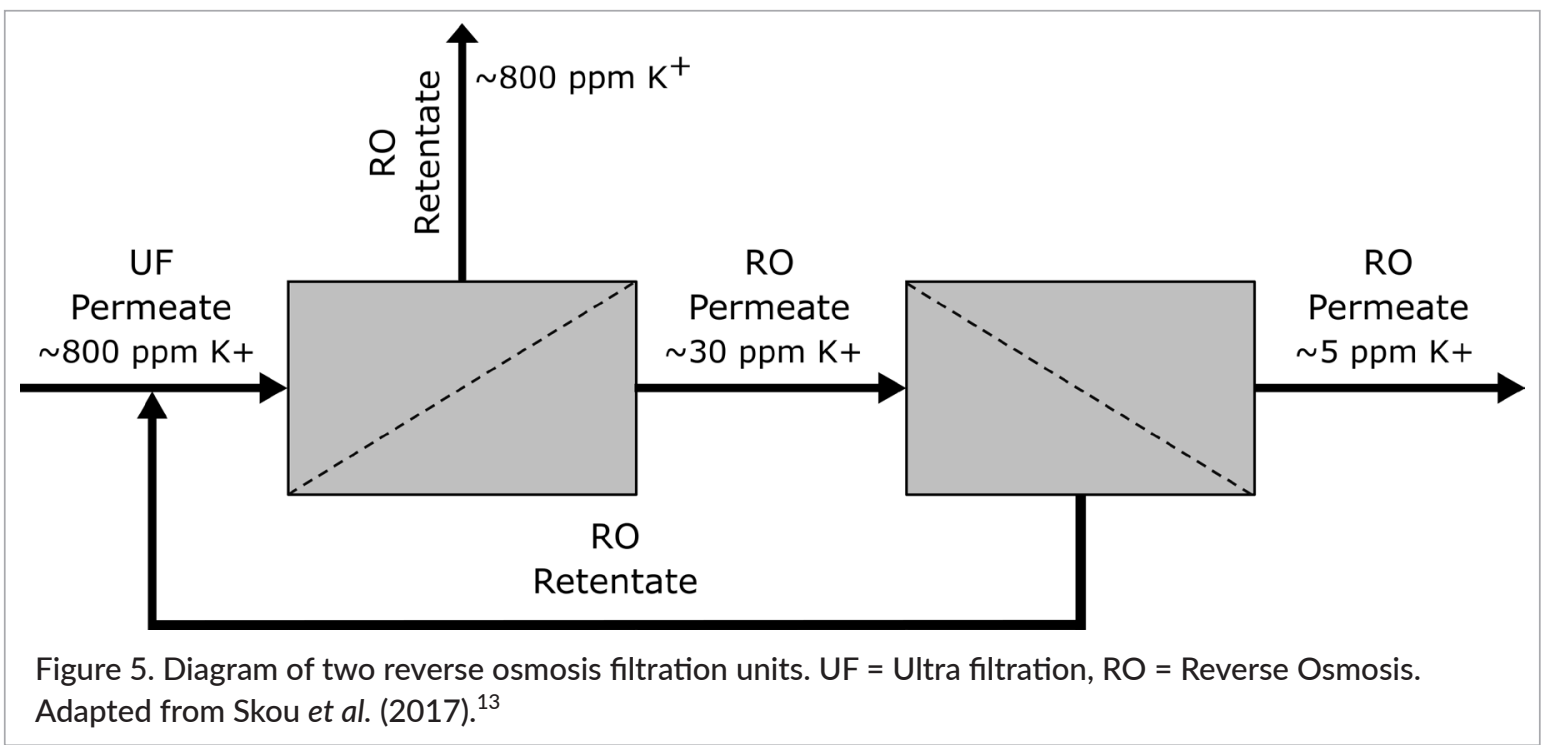

Figure 5). With RMSECVs of $181 \mathrm{ppm}$ and $115 \mathrm{ppm}$, in the concentration range from $0 \mathrm{ppm}$ to $1000 \mathrm{ppm}$, for the global temperature model and the individual $\mathrm{K}_{2} \mathrm{SO}_{4}$ model it would only be feasible to monitor the retentate of the first RO unit which is expected to have approximately $800 \mathrm{ppm}$ of potassium. However, this retentate also contain lactose concentrations of approximately 3-30\%, which could interfere with the salt predictions, especially because salt does not have a distinct signal but is modelled indirectly via the water absorbance spectrum. In this study we only measured on mono salt solutions, so further measurements on solutions having both salt and lactose is required in order to investigate if salt can be predicted in a lactose containing matrix.

Another implication of predicting salts in process streams is that there will normally be more than one salt dissolved. As mentioned above the models presented in this paper are made from spectral data from mono salt solutions. Therefore, they are not directly applicable to water streams containing mixtures of salts, as would be the scenario in many industries including food and pharmaceutical production. Additional experiments are needed in order to establish if the concentration of salts (or ions) can be predicted separately in solutions containing more than one salt.

\section{Conclusions}

This study has shown that the concentration of salt can be quantified by near-infrared spectroscopy. Spectral changes caused by temperature can be removed by PCA producing PLS models which can predict the salt concentration independently from temperature with an RMSECV of $186 \mathrm{ppm}$ and an $R^{2}$ of 0.67. Lower prediction errors can be obtained when data from one temperature and salt is applied to the model. The limit of detection for $\mathrm{K}_{2} \mathrm{SO}_{4}$ at $25^{\circ} \mathrm{C}$ were estimated to be $140 \mathrm{ppm}$ with a limit of quantification of $400 \mathrm{ppm}$. In most reverse osmosis filtration plants, the actual concentrations of salts will probably be too low for near-infrared spectroscopy to work as a process analyser for monitoring the salt content except perhaps for the retentate. Additional experiments are needed in order to establish whether salts in mixtures of more than one salt can be predicted.

\section{Funding}

This work was supported by the REuse of WAteR in the food and bioprocessing inDustries (REWARD) consortium funded by the Danish council for Strategic Research, Programme Commision on Health Food and Welfare.

\section{Acknowledgement}

The authors would like to acknowledge Q-interline $A / S$ and Anders Larsen for providing the Quant (ABB MB3600) spectrometer. 


\section{References}

1. T. Hirschfeld, "Salinity determination using NIRA", Appl. Spectrosc. 39(4), 740-741 (1985). https://doi. org/10.1366/0003702854250293

2. H.H. Holst, F. van den Berg and S.B. Engelsen, "Water reuse and saving in the food industry: a new frontier in food manufacturing", New Food 17(6), 49-53 (2014).

3. H.C. Jones and J.S. Guy, The Absorption Spectra of Solutions as Affected by Temperature and by Dilution: A Quantitative Study of Absorption Spectra by Means of the Radiomicrometer. Carnegie institution of Washington (1913).

4. A. Grant, A.M.C. Davies and T. Bilverstone, "Simultaneous determination of sodium hydroxide, sodium carbonate and sodium chloride concentrations in aqueous solutions by near-infrared spectrometry", Analyst 114(7), 819-822 (1989). https:// doi.org/10.1039/AN9891400819

5. J. Lin and C.W. Brown, "Near-IR spectroscopic determination of $\mathrm{NaCl}$ in aqueous solution", Appl. Spectrosc. 46(12), 1809-1815 (1992). https://doi. org/10.1366/0003702924123539

6. V.J. Frost and K. Molt, "Analysis of aqueous solutions by near-infrared spectrometry (NIRS) III. Binary mixtures of inorganic salts in water", J. Mol. Struct. 410, 573-579 (1997). https://doi.org/10.1016/ S0022-2860(96)09707-4

7. A.A. Gowen, F. Marini, Y. Tsuchisaka, S. De Luca, M. Bevilacqua, C. O'Donnell, G. Downey and R. Tsenkova, "On the feasibility of near infrared spectroscopy to detect contaminants in water using single salt solutions as model systems", Talanta 131,
609-618 (2015). https://doi.org/10.1016/j.talanta.2014.08.049

8. S. Wold, M. Sjöström and L. Eriksson, "PLSregression: a basic tool of chemometrics", Chemometr. Intell. Lab. Syst. 58(2), 109-130 (2001). https://doi.org/10.1016/S0169-7439(01)00155-1

9. R. Bro and A.K. Smilde, "Principal component analysis", Anal. Methods 6(9), 2812-2831 (2014). https:// doi.org/10.1039/C3AY41907J

10. A. McNaught and A. Wilkinson, Compendium of Chemical Terminology, $2^{\text {nd }}$ Edn. Blackwell Scientific Publications, Oxford, (1997).

11. H. Maeda, Y. Ozaki, M. Tanaka, N. Hayashi and T. Kojima, "Near infrared spectroscopy and chemometrics studies of temperature-dependent spectral variations of water: relationship between spectral changes and hydrogen bonds", J. Near Infrared Spectrosc. 3(4), 191-201 (1995). https://doi. org/10.1255/jnirs.69

12. V.H. Segtnan, S. Sasic, T. Isaksson and Y. Ozaki, "Studies on the structure of water using twodimensional near-infrared correlation spectroscopy and principal component analysis", Anal. Chem. 73(13), 3153-3161 (2001). https://doi.org/10.1021/ ac010102n

13. P.B. Skou, B. Khakimov, T.H. Hansen, S.D. Aunsbjerg, S. Knøchel, D. Thaysen and F. van den Berg, "Chemical characterization by gas chromatographymass spectrometry and inductively coupled plasmaoptical emission spectroscopy of membrane permeates from an industrial dairy ingredient production used as process water", J. Dairy Sci. 101(1), 135-146 (2017). https://doi.org/10.3168/jds.2017-12950 